Pesq. Vet. Bras. 35(Supl.1):33-38, dezembro 2015 DOI: $10.1590 /$ S0100-736X2015001300007

\title{
Computed tomographic features of the feline brain change with advancing age? ${ }^{1}$
}

\author{
Viviam R. Babicsak ${ }^{2 *}$, Guilherme S. Cardoso ${ }^{3}$, Miriam H. Tsunemi ${ }^{4}$ \\ and Luiz C. Vulcano ${ }^{2}$
}

\begin{abstract}
Babicsak V.R., Cardoso G.S., Tsunemi M.H. \& Vulcano L.C. 2015. Computed tomographic features of the feline brain change with advancing age? Pesquisa Veterinária Brasileira 35(Supl.1):33-38. Departamento de Reprodução Animal e Radiologia Veterinária, Faculdade de Medicina Veterinária e Zootecnia, Universidade Estadual Paulista Júlio de Mesquita Filho, Campus de Botucatu, Distrito de Rubião Júnior s/n, Botucatu, SP 18618-970, Brazil. E-mail: viviam.babicsak@gmail.com

A better understanding of normal or expected encephalic changes with increasing age in cats is needed as a growing number of these animals is attended in veterinary clinics, and imaging data referring to normal age-associated changes are extremely scarce in the literature. The objective of this study was to identify age-related changes in feline brain using CT imaging. Fifteen non-brachycephalic healthy cats with age between 1 to 6 years (adult group) and others over 12 years (geriatric group) were submitted to CT scan of the brain. Statistically significant differences were found between the groups for the ability to identify the left lateral ventricle and for falx cerebri calcification, both identified in a greater number of cats of the geriatric group. A significantly higher mean width of the third ventricle was also detected in geriatric animals. There were no statistically significant differences between lateral ventricular dimensions and encephalic parenchymal attenuation on pre and post-contrast CT phases. The results of the present study show an increase in the incidence of falx cerebri calcification and a third ventricular dilatation with advancing age in cats. Future researches using MRI scanners and a greater quantity of cats are needed in order to identify supplementary age-related changes.
\end{abstract}

INDEX TERMS: Cat, cerebral aging, computed tomographic imaging, neuroanatomy.

RESUMO.- [0 aspecto tomográfico do encéfalo de felinos altera com o avanço da idade?] Uma melhor compreensão das alterações encefálicas normais ou esperadas com o aumento da idade em gatos é necessária no presente momento, uma vez que tem havido um número crescente desses animais nas clínicas veterinárias, e dados de imagem referentes às alterações normais associadas à idade

\footnotetext{
${ }^{1}$ Received on January 1, 2015.

Accepted for publication on December 10, 2015.

${ }^{2}$ Departamento de Reprodução Animal e Radiologia Veterinária, Faculdade de Medicina Veterinária e Zootecnia (FMVZ), Universidade Estadual Paulista Júlio de Mesquita Filho (Unesp), Campus de Botucatu, Distrito de Rubião Júnior s/n, Botucatu, SP 18618-970, Brazil. *Corresponding author: viviam.babicsak@gmail.com

${ }^{3}$ Departamento de Clínicas Veterinárias, Hospital Veterinário, Universidade Estadual de Londrina (UEL), Campus Universitário, Cx. Postal 6001, Londrina, PR 86051-990, Brazil.

${ }^{4}$ Departamento de Bioestatística, Instituto de Biociências, Unesp, Campus de Botucatu, Distrito de Rubião Júnior s/n, Botucatu, SP 18618-970, Brazil.
}

são extremamente escassos na literatura. 0 objetivo deste estudo foi a identificação de alterações relacionadas à idade no encéfalo de gatos através da tomografia computadorizada. Quinze gatos saudáveis não braquicefálicos com idade entre 1 e 6 anos (grupo adulto) e mais de 12 anos (grupo geriátrico) foram submetidos à tomografia encefálica. Diferenças estatísticas significativas foram encontradas entre os grupos para a identificação do ventrículo lateral esquerdo e calcificação da foice cerebral, ambos visualizados em um número maior de gatos do grupo geriátrico. A média de largura do terceiro ventrículo também foi significativamente maior nos animais geriátricos. Não foram encontradas diferenças estatísticas significativas entre a mensuração dos ventrículos laterais e a atenuação do parênquima encefálico nas fases tomográficas pré e pós-contraste. Os resultados do presente estudo demonstram aumento da incidência de calcificação da foice cerebral e dilatação do terceiro ventrículo de acordo com o avanço da idade em gatos. Pesquisas futuras utilizando ressonância magnética e uma 
maior quantidade de gatos são necessárias a fim de se identificar alterações complementares relacionadas à idade.

TERMOS DE INDEXAÇÃO: Gatos, senilidade cerebral, tomografia computadorizada, neuroanatomia.

\section{INTRODUCTION}

Due to improvements in care by owners and advances in veterinary medicine, the number of older cats requiring medical care is increasing, and this results, therefore, in a need for a clearer understanding of age-related alterations in these animals. Several studies related to the normal aging brain have been performed in humans, allowing identification of abnormalities such as Alzheimer's disease where development is associated with amyloid-beta accumulation (Head 2001). Pathological age changes in the brain which occur with dementia are also assumed to occur in dogs and cats (Landsberg \& Araujo 2005). In these animals, amyloid-beta accumulation, which leads to vascular and perivascular changes, is considered one alteration responsible for clinical signs related to cognitive dysfunction (Cummings et al. 1996, Landsberg \& Araujo 2005). The identification of some neuroimaging findings has been used for the current diagnosis of Alzheimer's disease. These include global brain atrophy (Chan et al. 2001a), a reduced orbital frontal area (Resnick et al. 2003) and temporal lobe, in particular in the hippocampal region (Chan et al. 2001b). It was seen that these neuroimaging findings are usually greater in humans with Alzheimer's disease than in normal aging individuals, highlighting, therefore, how important is the knowledge of normal changes in aging brain. In cats, little is known about the effects of normal aging, thus, the objective of this study was to demonstrate normal age-associated changes in the brain of individuals of this specie using computed tomographic (CT) imaging.

\section{MATERIALS AND METHODS}

Ethics approval was obtained from Ethics Committee on Animal Experimentation of the School of Veterinary Medicine and Animal Sciences of São Paulo State University (Protocol number 01/2011).

Thirty cats were divided into two groups based on age according to the published classification of the feline life stages (Fortney 2012). The adult group included 15 animals with ages ranging from 1 to 6 years while the geriatric group was composed entirely of 15 cats over 12 years of age. All subjects were non-brachycephalic mixed breed animals.

Inclusion in the study was based on the following criteria. A clinical history was obtained from the owners to rule out any previous neurological symptoms. After a general and neurological physical examination, only healthy cats (without cognitive dysfunction) were considered eligible. A complete blood examination including white cell count along with biochemical exams for urea, creatinine, aspartate aminotransferase, alkaline phosphatase, gamma glutamyl transferase, total plasma protein, albumin and globulin was also done and animals with normal values were selected. Polymerase chain reaction tests for feline immunodeficiency and leukaemia virus were also performed and only cats considered negative were included in this study.

All cats were anaesthetized for the CT exam, prior to which they were denied access to water and food for 2 and 12 hours, respectively. After the clinical examination, cats were premedicated with intramuscular acepromazine 0.2\% (Apromazin; Syntec do Brasil, Cotia, SP, Brazil) at $0.05 \mathrm{mg} / \mathrm{kg}$ and morphine sulphate (Dimorf; Cristália, Itapira, SP, Brazil) at $0.3 \mathrm{mg} / \mathrm{kg}$. Twenty minutes later, catheterization of the cephalic vein was performed to administer intravenous physiologic saline NaCl 0.9\% (Sanobiol; Pouso Alegre, MG, Brazil) at a rate of $5 \mathrm{ml} / \mathrm{kg} / \mathrm{h}$. This was followed by anaesthetic induction using intravenous propofol (Propovan; Cristália, Itapira, SP, Brazil) at $6.0 \mathrm{mg} / \mathrm{kg}$ or until loss of the laryngotracheal reflex. After this, oral tracheal intubation was performed and the tracheal tube connected to a Bain circuit, with oxygen flow between 1 and $2 \mathrm{~L} / \mathrm{min}$. The vaporiser with isoflurane (Isoforine; Cristália, Itapira, SP, Brazil) was adjusted to maintain a moderate depth of anaesthesia.

The CT examination was performed using a single-slice helical CT scanner (SCT-7800 CT; Shimadzu, Kyoto, Japan). The animal was positioned in sternal recumbency and the head was symmetrically positioned on a lined cushion. Standard transverse slices of the area between the olfactory bulb and the foramen magnum were obtained using 90 milliamperes per second (mAs) and 120 kilovolt $(\mathrm{kVp})$ in supratentorial region and $100 \mathrm{mAs}$ and $120 \mathrm{kVp}$ in infratentorial portion. Images were reconstructed with a slice thickness and increment of $2 \mathrm{~mm}$ in the first region $(2 \times 2)$ and 1 $\mathrm{mm}$ in the last section $(1 \mathrm{x} 1)$. Following the non-contrast phase, contrast-enhanced CT scan was performed by administering intravenous iopamidol (Iopamiron 300; Bracco, Milan, Italy) at $2 \mathrm{ml} / \mathrm{kg}$ through the cephalic vein catheter. Tomographic scan was started about ten seconds after the contrast was completely injected.

Images were evaluated using a software program for medical imaging analysis (Clear Canvas; Clear Canvas Inc., Toronto, Ontario, Canada) by a radiologist blinded to the age and other identifications.

The categorical variables analyzed in this study included the possibility of identification of the right and left lateral ventricles, third ventricle and temporal ventricular horn. The fourth ventricle and the mesenencephalic aqueduct were not evaluated due to the beam hardening artifact in the region. Calcification of the falx cerebri, observed as a hyperattenuating flat plaque in dorsal midline region of the brain on pre-contrast scan, was evaluated for presence. Parenchymal texture and contrast enhancement patterns were also analyzed.

In continuous assessment, all measurements were performed in triplicate and then an average value was calculated. The height of the right and left lateral ventricles and the width of the third ventricle and visible temporal horn were measured in the area of the largest ventricular dimension (Fig.1). The attenuation values

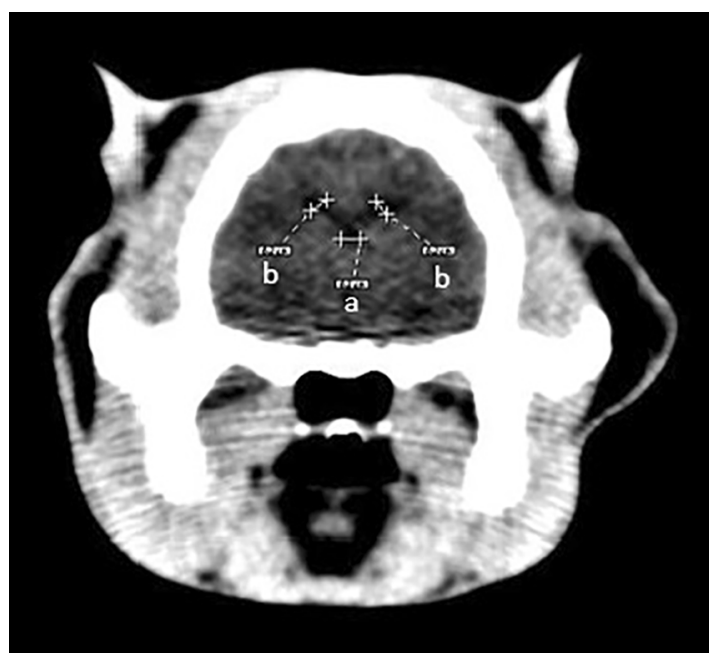

Fig.1. Tomographic images illustrating the measurement of the third ventricle (a) and lateral ventricles (b). 


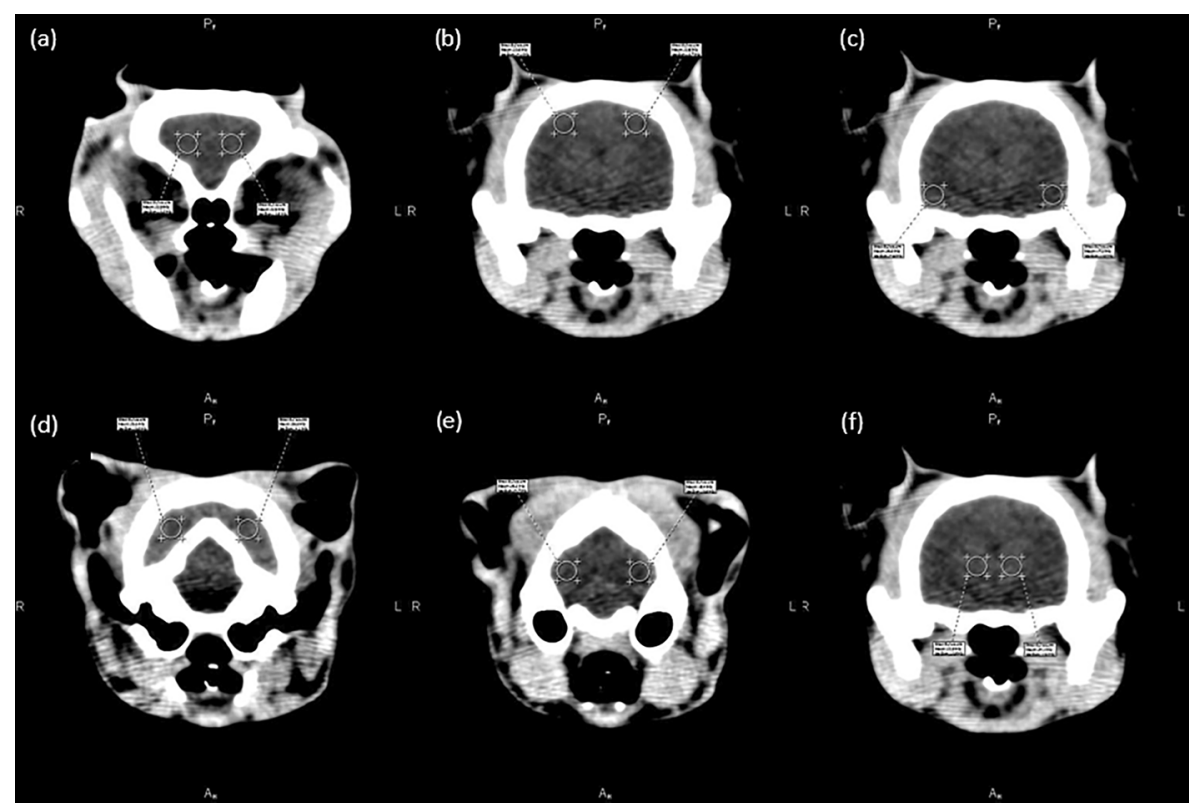

Fig.2. Tomographic images demonstrating the local the circular ROIs were placed for attenuation measurement in frontal (a), parietal (b), temporal (c) and occipital lobes (d), and in cerebellum and thalamus (f).

of the frontal, parietal, temporal and occipital lobes, thalamus and cerebellum in both hemispheres were also measured on pre and post-contrast images. These values were derived from the attenuation measurements of circular regions of interest (ROIs) with a cross-sectional area of $0.2 \mathrm{~cm}^{2}$. ROIs were placed in the same loci in all animals based on anatomical reference sites, which were usually adjacent bony structures (Fig.2). The encephalic height was measured by placing the calipers at the ventral and dorsal encephalic limits in midline region in tomographic image at the level of the thalamus and hypophysis.

Statistical analysis was performed by use of a statistical program (SPSS 17.0; SPSS Inc., Chicago, IL, USA). The data were considered normally distributed and the statistical analysis used for this evaluation was Kolmogorov-Smirnov test. T test was used to identify differences in the weight and encephalic height between the groups. Fisher Exact and Chi Square tests were performed to detect statistically significant differences in categorical variables. Differences in ventricular dimensions between the groups were tested by $\mathrm{T}$ test for independent samples. Differences between the attenuation values of the right and left cerebral areas were tested by the T test for dependent samples. Since no statistically significant differences were found, the attenuation values determined in the right and left hemispheres were summed and then, a mean value was calculated for each area. Differences in mean CT attenuation of brain regions between the groups were tested by $\mathrm{T}$ test for independent samples. Statistical level of significance for all tests was set at $5 \%(\mathrm{P}<0.05)$.

\section{RESULTS}

In adult group, 6/15 were males (5/6 castrated) and 9/15 were females ( $9 / 9$ neutered). The mean age and weight of the cats were $2.87 \pm 1.85$ years (ranging from 1 to 6 years) and $3.92 \pm 1.03 \mathrm{~kg}$, respectively. The mean value related to the encephalic height was $2.62 \mathrm{~cm}$ and the standard deviation was $0.10 \mathrm{~cm}$.

In geriatric group, $2 / 15$ were males (2/2 castrated) and $13 / 15$ were females (13/13 neutered). The mean age of the animals was $14.33 \pm 2.06$ years (ranging from 12 to 17 years) and the mean values related to the weight and encephalic height were $3.32 \pm 0.62 \mathrm{~kg}$ and $2.60 \pm 0.11 \mathrm{~cm}$ respectively.

Comparing mean weight $(\mathrm{P}=0.062)$ and encephalic height $(\mathrm{P}=0.526)$, no statistically significant differences were found between the groups, suggesting that the brain dimensions of the adult and geriatric cats were similar.

The third ventricle could be identified in 15/15 animals of both groups $(\mathrm{P}=1.000)$. The right lateral ventricle could be seen in 5/15 individuals of the first group and in $10 / 15$ subjects of the second group $(\mathrm{P}=0.143)$. The left lateral ventricle could be visualized in $2 / 15$ adult cats and in $10 / 15$ geriatric animals $(\mathrm{P}=0.008)$. Both right and left lateral ventricles could be identified in a greater proportion of cats of geriatric group in comparison with the adult one, however, a statistically significant difference was found only for the left lateral ventricle. The right temporal horn could be identified in 2/15 animals of the first group and $1 / 15$ cat of the second group. The left temporal horn could not be visualized in any subject of both groups.

Calcification of the falx cerebri was identified in 4/15 adult animals and 11/15 geriatric cats and a statistically significant difference was found between the groups $(\mathrm{P}=0.027)$.

Differences in tomographic texture and contrast enhancement patterns between the adult and geriatric cats were not identified since all of them showed a homogenous texture and none showed abnormal contrast uptakes in cerebral parenchyma.

In ventricular continuous assessment (Table 1), a greater mean width of the third ventricle was found in the geriatric group, showing a statistically significant difference between the groups. Figure 3 shows scatter-plots correlating the width of the third ventricle and the age of all cats 
Table 1. Means (cm), standard deviations $(\mathrm{cm})$ and $P$ values related to the measurements of the third ventricle, lateral ventricles and right temporal horn

\begin{tabular}{lcccc}
\hline Cerebral ventricles & Groups & Mean & $\begin{array}{c}\text { Standard } \\
\text { deviation }\end{array}$ & P value \\
\hline Third ventricle & Adult & 0.16 & 0.03 & $0.003^{*}$ \\
& Geriatric & 0.22 & 0.07 & \\
Right lateral ventricle & Adult & 0.22 & 0.09 & 0.563 \\
& Geriatric & 0.20 & 0.05 & \\
Left lateral ventricle & Adult & 0.17 & 0.07 & 0.323 \\
& Geriatric & 0.22 & 0.06 & \\
Right temporal horn & Adult & 0.33 & 0.05 & 0.394 \\
& Geriatric & 0.24 & - &
\end{tabular}

* Statistically significant difference between groups $(\mathrm{P}<0.05)$.

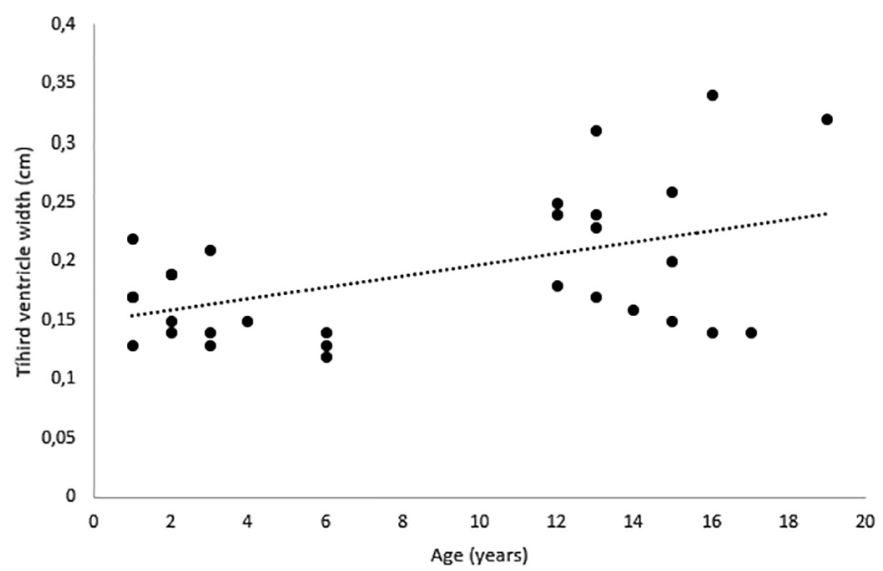

Fig.3. Scatter-plots correlating the third ventricular measurement and the age of the adult and geriatric cats, illustrating, therefore, the enlargement of the third ventricle with advancing age.

included in this study. Considering the lateral ventricular measurements, no statistically significant differences were found between the groups. Based on the mean ventricular dimensions of the adult cats, greater sizes of the third ventricle and right and left lateral ventricles were identified in $11 / 15,5 / 15$ and $8 / 15$ geriatric subjects, respectively. Regarding the width of the visible right temporal horn, a greater mean value was found in the adult group in comparison with the geriatric group, however, no statistically significant differences were identified.

Table 2. Means (Hounsfield unit - HU), standard deviations (HU) and $P$ values referring to the attenuation of the encephalic parenchyma on non-contrast CT phase

\begin{tabular}{lcccc}
\hline Brain regions & Groups & Mean & $\begin{array}{c}\text { Standard } \\
\text { deviation }\end{array}$ & P value \\
\hline Frontal & Adult & 25.20 & 1.44 & 0.164 \\
Parietal & Geriatric & 26.60 & 3.10 & \\
& Adult & 28.47 & 2.35 & 0.569 \\
Temporal & Geriatric & 27.84 & 2.88 & \\
& Adult & 22.19 & 2.34 & 0.454 \\
Occipital & Geriatric & 22.95 & 2.50 & \\
& Adult & 24.36 & 2.74 & 0.756 \\
Cerebellum & Geriatric & 24.67 & 2.17 & \\
& Adult & 22.27 & 1.18 & 0.070 \\
Thalamus & Geriatric & 23.34 & 1.50 & \\
& Adult & 24.57 & 1.29 & 0.131 \\
& Geriatric & 23.35 & 2.41 &
\end{tabular}

Table 3. Means (HU), standard deviations (HU) and P values related to the encephalic attenuation on post-contrast CT examination

\begin{tabular}{lcccc}
\hline Brain regions & Groups & $\begin{array}{c}\text { Mean } \\
\text { deviation }\end{array}$ & Standard & P value \\
\hline Frontal & Adult & 29.23 & 2.07 & 0.440 \\
& Geriatric & 29.95 & 2.39 & \\
Parietal & Adult & 34.42 & 2.61 & 0.114 \\
& Geriatric & 32.55 & 2.91 & \\
Temporal & Adult & 26.17 & 2.07 & 0.945 \\
& Geriatric & 26.23 & 2.12 & \\
Occipital & Adult & 28.45 & 2.43 & 0.744 \\
& Geriatric & 28.16 & 1.91 & \\
Cerebellum & Adult & 25.71 & 1.46 & 0.339 \\
& Geriatric & 26.36 & 1.73 & \\
Thalamus & Adult & 29.54 & 1.35 & 0.189 \\
& Geriatric & 28.48 & 2.26 &
\end{tabular}

On pre and post-contrast CT phases, there were no statistically significant differences in cerebral attenuation between the groups (Table 2 and 3).

\section{DISCUSSION}

In the present study, the lateral ventricles were identified in a greater proportion of cats of the geriatric group compared with the adult one. The statistically significant difference between the groups found for the left lateral ventricular identification suggests that an enlargement of this structure occurs with age, enabling, therefore, its identification on tomographic images. The possible enlargement of the left ventricle in cats may occur secondarily to an asymmetric cerebral atrophy, more pronounced in left hemisphere. In humans, a prominent volumetric reduction of the left temporal lobe in comparison with the right was reported in a previous study (Resnick et al. 2003).

Ventricle temporal horn enlargement, however, was visualized in a greater number of adult animals, indicating that the temporal horns of cats do not suffer a dilatation with age in the same proportion as in dogs. In the study of Pugliese et al. (2010), it was found that the temporal horn enlargement, which characterizes hippocampal atrophy along with a reduced height of hippocampus, may be considered an early marker of cerebral aging in dogs. One explanation to this occurrence in cats is that maybe these animals exhibit a slow progress in the rate of hippocampal atrophy. Further investigations related to hippocampal atrophy in aging cats are needed.

Calcification of the falx cerebri, an incidental finding secondarily to metaplasia and bony differentiation of falx cerebri multipotent cells, was observed in both groups; however, its incidence was significantly higher in geriatric group. This finding is consistent with those verified in humans, in which a significant positive correlation was identified between age and the frequency of falx cerebri calcification (Daghighi et al. 2007).

In ventricular continuous assessment, a higher mean value related to the third ventricular size was determined in geriatric group. The existence of a statistically significant difference between the groups proves that the third ventricle enlarge with age in cats, possibly due to cerebral 
atrophy, which normally occurs in aging in consequence to neuronal atrophy (Terry et al. 1987), demyelination and a decrease in the number of myelinated fibres (Marner et al. 2003). The third ventricular enlargement identified in the cats of the present study is not in agreement with the results of a research study performed in dogs by Gonzáles-Soriano et al. (2001), who did not find any difference in the size of the third ventricle between younger and older adult German Shepherds. However, the information found in the cats corroborates that verified in humans, in which the third ventricle, that may not be seen or may have very small dimensions in individuals under 40 years of age, can usually be clearly and easily identified in persons over 50 years old (LeMay 1984). Based on the mean third ventricular dimension of the adult group, a greater third ventricle size was found in $73.33 \%(11 / 15)$ of the geriatric cats. This value is higher than the $65 \%(13 / 20)$ incidence associated to general ventricular enlargement found in dogs by Borràs et al. (1999).

Considering the lateral ventricular measurements, no statistically significant differences between the groups were verified for the height. In German Shepherd dogs, however, it was found that the size of the lateral ventricles suffers a significantly increase according to the age (Gonzáles-soriano et al. 2001). In the study performed by Su et al. (2005), a lateral ventricular enlargement was also observed in 26/47 (55.32\%) and 35/41 (85.37\%) Beagle dogs in the second and third year of their longitudinal study, respectively. As well as in dogs, an increase in the size of the lateral ventricles was also verified in humans (Sullivan et al. 2002, Scahill et al. 2003). Lateral ventricular enlargement was not identified in the cats of this study and one reason for it is that maybe the lateral ventricular dilatation occurs in a later phase of aging in cats, secondly to the third ventricular enlargement.

On pre-contrast CT phase, the absence of statistically significant differences between mean attenuation values of the groups differs from the findings identified in humans. In these individuals, a reduction in CT attenuation occurs with advancing age as identified in the study performed by Meyer et al. (1994). The decrease in CT attenuation is possibly related to a synaptic attenuation decline, which is known to occur in normal aging (Masliah et al. 1993), and is coupled with a reduction in the cerebral perfusion (Meyer et al. 1994). The blood flow decline may occur due to a decrease in the distensibility of the vessel wall secondary to changes in vascular innervation and responsiveness (Nobler et al. 1999) and/or amyloid angiopathy (Prior et al. 1996). In addition, the decrease in cerebral blood flow may be explained by a decline of local requirements for energy and oxygen due to tissue loss or reduction (Peremans et al. 2002). In the study performed by Hasan et al. (2013), it was concluded that the cerebral blood flow of humans reduces with age in the totality of grey matter. In dogs, however, it was noted a regional decrease of cerebral blood flow in fronto- and temporocortical area and in the subcortical region with age (Peremans et al. 2002). As brain attenuation is coupled with cerebral blood flow (Meyer et al. 1994), we speculate that the geriatric cats of our study possibly did not exhibit a significant reduction in cerebral perfusion. One reason for this occurrence is that maybe cats manifest a slow progress in the development of these conditions that lead to a reduction in cerebral blood flow, such as amyloid angiopathy. As part of the evidence supporting this speculation, previous reports described the presence of feline plaques solely in the brain of very aged cats (17-21 years old) (Nakamura et al. 1996, Papaioannou 2014). Individuals older than 17 years old were not evaluated in the present study.

On contrast-enhanced CT, no significant differences in cerebral attenuation were identified between the groups. Since the interstitial enhancement of the cerebral parenchyma is dependent of the blood-brain barrier (BBB) (Sage et al. 1998), this finding indicates absence of alterations in the BBB permeability of the geriatric cats. In CT studies performed by Caserta et al. (1998) and Dysken et al. (1990), abnormalities in BBB were not identified in elderly humans as well as in the cats of this study. Nevertheless, it is known that several age-related factors contribute to an increase in BBB permeability in humans such as oxidative stress (Popescu et al. 2009) and amyloid angiopathy (Prior et al. 1996). As previously described, the exclusive presence of feline plaques in the brain of very aged cats (Nakamura et al. 1996, Papaioannou 2014) supports the evidence of a possible elevation in BBB permeability in a later stage of cat's life.

As conclusion, the present study showed that the incidence of falx cerebri calcification and the width of the third ventricle increase according to age in cats. Some limitations and potential shortcomings occurred in this study such as the utilization of a reduced number of animals. Another limitation factor was the use of CT imaging since, due to the low contrast of soft tissue of this modality compared to MRI, some changes may not be identified. Possible confounding variables such as sex, neuter state, weight and encephalic height were not controlled in this study. However, no significant differences were observed between the weight and encephalic heights of the groups, suggesting that the cerebral size of the animals of both groups were similar. Further transversal and longitudinal investigations using MRI scanners and a greater number of animals are necessary to determine additional changes associated with age in the animals of this specie.

Acknowledgements.- The authors are grateful for financial support provided (Proc. 2011/21130-4) and for the Master's student grant (Proc. 2010/11772-6) given by the Aid to Research Foundation of the State of São Paulo (Fundação de Amparo à Pesquisa do Estado de São Paulo -FAPESP).

\section{REFERENCES}

Borràs D., Ferrer I. \& Pumarola M. 1999. Age-related changes in the brain of the dog. Vet. Pathol. 36:202-211.

Caserta M.T., Caccioppo D., Lapin G.D., Ragin A. \& Groothuis D.R. 1998. Blood-brain barrier integrity in Alzheimer's disease patients and elderly control subjects. J. Neuropsychiatry Clin. Neurosci. 10:78-84.

Chan D., Fox N.C., Jenkins R., Scahill R.I., Crum W.R. \& Rossor M.N. 2001a. Rates of global and regional cerebral atrophy in AD and frontotemporal dementia. Neurology 57:1756-1763.

Chan D., Fox N.C., Scahill R.I., Crum W.R., Whitwell J.L., Leschziner G., Ros- 
sor A.M., Stevens J.M., Cipolotti L. \& Rossor M.N. 2001. Patterns of temporal lobe atrophy in semantic dementia and Alzheimer's disease. Ann. Neurol. 49:433-442.

Cummings B.J., Head E., Ruehl W., Milgram N.W. \& Cotman C.W. 1996. The canine as an animal model of human aging and dementia. Neurobiol. Aging 17:259-268.

Daghighi M.H., Rezaei V., Zarrintan S. \& Pourfathi H. 2007. Intracranial physiological calcifications in adults on computed tomography in Tabriz, Iran. Folia Morphol. (Warsz). 66:115-119.

Dysken M.W., Nelson M.J., Hoover K.M., Kuskowski M. \& McGeachie R. 1990. Rapid dynamic CT scanning in primary degenerative dementia and age-matched controls. Biol. Psychiatry 28:425-434.

Gonzáles-Soriano J., García M., Contreras-Rodriguez J., Martínez-Saintz P. \& Rodrigués-Veiga E. 2001. Age-related changes in the ventricular system of the dog brain. Ann. Anat. 183:283-291.

Fortney W.D. 2012. Implementing a successful senior/geriatric health care program for veterinarians, veterinary technicians, and office managers. Vet. Clin. North Am. Small Anim. Pract. 42:823-834.

Hasan K.M., Ali H. \& Shad M.U. 2013. Atlas-based and DTI-guided quantification of human brain cerebral blood flow: feasibility, quality assurance, spatial heterogeneity and age effects. Magn. Reson. Imaging 31:14451452.

Head E. 2001. Brain aging in dogs: parallels with human brain aging and Alzheimer's disease. Vet. Therapeutic 2:247-260.

Landsberg G.M. \& Araujo J.A. 2005. Behavior problems in geriatric pets. Vet. Clin. North Am., Small Anim. Pract. 35:675-698.

LeMay M. 1984. Radiologic changes of the aging brain and skull. Am. J. Roentgenol. 143:383-389.

Marner L., Nyengaard J.R., Tang Y. \& Pakkenberg B. 2003. Marked loss of myelinated nerve fibers in the human brain with age. J. Comp. Neurol. 462:144-152.

Masliah E., Mallory M., Hanson L., DeTeresa R. \& Terry R.D. 1993. Quantitative synaptic alteration $\mathrm{m}$ the human neocortex during normal aging. Neurol. 43:192-197.

Meyer J.S., Takashima S., Terayama Y., Obara K., Muramatsu K. \& Weather S. 1994. CT changes associated with normal aging of the human brain. J. Neurol. Sci. 123:200-208.

Nakamura S., Nakayama H., Kiatipattanasakul W., Uetsuka K., Uchida K. \& Goto N. 1996. Senile plaques in very older adult cats. Acta Neuropathol. 91:437-439.
Nobler M.S., Mann J.J. \& Sackeim H.A. 1999. Serotonin, cerebral blood flow and cerebral metabolic rate in the geriatric major depression and normal aging. Brain Res. Rev. 30:250-263.

Papaioannou N. 2014. Principles of age-related changes in the canine and feline brain. Acta Vet. Beograd 64:1-9.

Peremans K., Audenaert K., Blanckaert P., Jacobs F., Coopman F., Verschooten F., Van Bree H., Van Heeringen C., Mertens J., Slegers G. \& Dierckx R. 2002. Effects of aging on brain perfusion and serotonin-2A receptor binding in the normal canine brain measured with single photon emission tomography. Prog. Neuropsychopharmacol. Biol. Psychiatry 26:13931404.

Popescu B.O., Toescu E.C., Popescu L.M., Bajenaru O., Muresanu D.F., Schultzberg M. \& Bogdanovic N. 2009. Blood-brain barrier alterations in ageing and dementia. J. Neurol. Sci. 283:99-106.

Prior R., D’Urso D., Frank R., Prikulis I. \& Pavlakovic G. 1996. Loss of vessel wall viability in cerebral amyloid angiopathy. NeuroReport 7:562564.

Pugliese M., Carrasco J.P., Gomez-anson B., Andrade C., Zamora A., Rodríguez M.J., Mascort J. \& Mahy N. 2010. Magnetic resonance imaging of cerebral involutional changes in dogs as markers of aging: an innovative tool adapted from a human visual rating scale. Vet. J. 186:166-171.

Resnick S.M., Pham D.L., Kraut M.A., Zonderman A.B. \& Davatikos C. 2003. Longitudinal magnetic resonance imaging studies of older adults: a shrinking brain. J. Neurosci. 23:3295-3301.

Sage M.R., Wilson A.J. \& Scroop R. 1998. Contrast media and the brain: the basis of CT and MR imaging enhancement. Neuroimaging Clin. N. Am. 8:695-707.

Scahill R.I., Frost C., Jenkins R., Whitwell J.L., Rossor M.N. \& Fox N.C. 2003. A longitudinal study of brain volume changes in normal aging using serial registered magnetic resonance imaging. Arch. Neurol. 60:989-994.

Su M.-Y., Tapp P.D., Vu L., Chen Y.-F., Chu Y., Muggenburg B., Chiou J.Y., Chen C., Wang J., Bracco C. \& Head E. 2005. A longitudinal study of brain morphometrics using serial magnetic resonance imaging analysis in a canine model of aging. Prog. Neuropsychopharmacol. Biol. Psychiatry 29:389-397.

Sullivan E.V., Pfefferbaum A., Adalsteinsson E., Swan G.E. \& Carmelli D. 2002. Differential rates of regional brain change in callosal and ventricular size: a 4-year longitudinal MRI study of elderly men. Cereb. Cortex 12:438-445.

Terry R.D., DeTeresa R. \& Hansen L.A. 1987. Neocortical cell counts in normal human younger adult aging. Ann. Neurol. 21:530-539. 